\title{
Material didático adaptado para o ensino de Higiene e Saúde: Jogo da Memória Saudável para alunos com Transtorno do Espectro Autista (TEA)
}

\author{
Didactic material adapted for the teaching of Hygiene and Health: Healthy Memory game for
} students with Autism Spectrum Disorder (ASD)

Material didáctico adaptado para la enseñanza de la hHigiene y la Salud: Juego de memoria saludable para estudiantes con trastorno del espectro autista (TEA)

\section{Resumo}

Desenvolver hábitos de Higiene e Saúde nas crianças com Transtorno do Espectro do Autismo (TEA) é desafiador devido a esses indivíduos apresentarem inabilidade persistente na comunicação e interação social, acrescido, frequentemente, de disfunções sensoriais. Esta dificuldade se torna mais evidente quando chega a idade escolar onde se faz necessária a aprendizagem de conceitos socialmente construídos, justamente por necessitar de interação com seus pares. Neste sentido, o conteúdo contemplado neste trabalho está relacionado aos conceitos de Higiene e Saúde trabalhados de forma lúdica através do jogo da Memória Saudável para apoio à aprendizagem de alunos com TEA. Participaram desta pesquisa alunos autistas com dificuldades na comunicação verbal matriculados desde a Educação Infantil até o $4^{\circ}$ ano do Ensino Fundamental e os professores mediadores das salas de recursos multifuncionais. O presente estudo caracterizou-se como qualitativo, uma vez que avaliou o comportamento, as falas e experiências dos sujeitos envolvidos. O instrumento de coleta de dados utilizado foi a observação direta realizada pelo professorpesquisador. Para utilização do jogo, os alunos precisaram parear vinte cartelas, sendo dez com desenhos onde haviam situações de risco relacionadas à saúde e outras dez com bons hábitos de higiene. Os resultados obtidos demonstraram: i) que o número de peças menores favoreceu a compreensão; ii) que houve a necessidade de usar contraste de cores, como amarelo e vermelho, além da simplificação das imagens e, iii) que o jogo funcionou como verificador da aprendizagem dos alunos que tinham vivências anteriores com o material de higiene e/ou realizavam autocuidados com autonomia. Estes dados reforçaram a hipótese do jogo como comunicação para a aprendizagem das atividades básicas de vida diária (ABVD) e sua relação com a saúde, tão essenciais para os autistas com baixa funcionalidade da verbalização. Dessa forma, podemos indicar o uso do jogo integral ou de forma flexível, com a redução do número de cartelas ou seleção daquelas indicadas ao público alvo para construção do pensamento simbólico sobre o tema de Higiene e Saúde.

Palavras-chave: Ensino de higiene e saúde; Educação inclusiva; Autismo; Jogos educativos. 


\begin{abstract}
Developing hygiene and health habits in children with Autism Spectrum Disorder (ASD) is challenging because these individuals have persistent inability in communication and social interaction, often added to sensory dysfunctions. This difficulty becomes more evident when school age arrives, where the learning of socially constructed concepts is necessary, precisely because they need interaction with their peers. In this sense, the content covered in this work is related to the concepts of Hygiene and Health worked in a playful way through the Healthy Memory game to support the learning of students with ASD. Autistic students with difficulties in verbal communication, enrolled from Kindergarten to the 4th year of Elementary School, and the mediators of the multifunctional resource rooms participated in this research. The present study was characterized as qualitative, as it evaluated the behavior, speeches and experiences of the subjects involved. The data collection instrument used was direct observation carried out by the professor-researcher. To use the game, students needed to pair twenty cards, ten with drawings where there were health-related risk situations and another ten with good hygiene habits. The results obtained showed: i) that the number of smaller pieces favored understanding; ii) that there was a need to use color contrast, such as yellow and red, in addition to simplifying the images and, iii) that the game worked as a verification of learning for students who had previous experiences with hygiene material and/or performed self-care with autonomy. These data reinforced the hypothesis of the game as communication for learning basic activities of daily living (BADL) and its relationship with health, so essential for autistic people with low verbalization functionality. Thus, we can indicate the use of the game in its entirety or in a flexible way, with a reduction in the number of cards or selection of those indicated for the target audience for the construction of symbolic thinking on the theme of Hygiene and Health.
\end{abstract}

Keywords: Hygiene and health training; Inclusive education; Autism; Educational games.

\title{
Resumen
}

Desarrollar hábitos de higiene y salud en niños con trastorno del espectro autista (TEA) es un desafío porque estos individuos tienen una incapacidad persistente en la comunicación y la interacción social, que a menudo se suma a disfunciones sensoriales. Esta dificultad se hace más evidente cuando llega la edad escolar, donde es necesario el aprendizaje de conceptos construidos socialmente, precisamente porque necesitan la interacción con sus pares. En este sentido, el contenido cubierto en este trabajo está relacionado con los conceptos de Higiene y Salud trabajados de manera lúdica a través del juego Memoria Saludable para apoyar el aprendizaje de los estudiantes con TEA. En esta investigación participaron estudiantes autistas con dificultades en la comunicación verbal, matriculados desde el jardín de infancia hasta el $4^{\circ}$ año de la escuela primaria, y los mediadores de los salones de recursos multifuncionales. El presente estudio se caracterizó como cualitativo, ya que evaluó el comportamiento, los discursos y las experiencias de los sujetos involucrados. El instrumento de recolección de datos utilizado fue la observación directa realizada por el profesor investigador. Para utilizar el juego, los alumnos necesitaron emparejar veinte cartas, diez con dibujos donde existían situaciones de riesgo relacionadas con la salud y otras diez con buenos hábitos de higiene. Los resultados obtenidos mostraron: i) que el número de piezas más pequeñas favoreció la comprensión; ii) que existía la necesidad de utilizar contraste de colores, como el amarillo y el rojo, además de simplificar las imágenes y, iii) que el juego funcionaba como una verificación del aprendizaje para los alumnos que tenían experiencias previas con material de higiene y / o realizaban autocuidado con autonomía. Estos datos refuerzan la hipótesis del juego como comunicación para las actividades básicas de aprendizaje de la vida diaria (ABVD) y su relación con la salud, tan esencial para las personas autistas con baja funcionalidad de verbalización. Así, podemos indicar el uso del juego en su totalidad o de forma flexible, con una reducción en el número de cartas o selección de las indicadas para el público objetivo público objetivo para la construcción del pensamiento simbólico sobre el tema Higiene y Salud.

Palabras clave: Formación en higiene y salud; Educación inclusiva; Autismo; Juegos educativos.

\section{Introdução}

A década de 90 do século passado foi marcada por movimentos de inclusão e a sociedade ouviu de modo mais intenso, sobre outra postura a ser assumida, em relação ao diferente e à necessidade de adaptar-se à diferença, seja ela como for. Ao longo deste tempo surgiram amplas discussões sobre a inclusão social, digital, de gênero, de orientação sexual, dentre outras, na tentativa de promover a ampliação do debate e o olhar para a necessidade ao respeito às diferenças (Mantoan, 2005).

A partir da Conferência de Jomtien, na Tailândia (artigo 5, 1990) e de Salamanca (1994) (Foucault, 2001), a inclusão passou a ser amplamente discutida e defendida. A escola, como espaço social de fato, foi inserida na discussão e provocada a adaptar-se também para receber pessoas com deficiências.

Apesar de termos o tema em discussão há quase três décadas, muitos docentes ainda dizem repetidamente que não se sentem preparados para atender às necessidades pedagógicas dos alunos com deficiência, ou que se sentem desamparados ao recebê-los, por não saberem o que fazer para ensinar. 
Neste contexto, temos o autismo, um transtorno do neurodesenvolvimento que desafia o professor em suas práticas pedagógicas, exigindo novas estratégias e propostas curriculares para construir os processos de ensino e aprendizagem de forma a atender a diversidade apresentada pelos alunos público alvo da Educação Especial, tal como os autistas (Glat \& Pletsch, 2013).

Assim, nesse artigo abordaremos inicialmente as características gerais do autismo, o tema higiene e saúde na educação especial e a atividade lúdica como estratégia para o desenvolvimento da criança, finalizando com os dados da pesquisa de campo realizada no âmbito do Mestrado Profissional em Diversidade e Inclusão (CMPDI) da Universidade Federal Fluminense (UFF). Adicionalmente discutiremos a importância da ludicidade para aprendizagem de crianças inseridas no transtorno do espectro do autismo que apresentam de moderada à severa dificuldade de comunicação verbal, utilizando-se de um jogo da memória para trabalhar a temática da Higiene e Saúde, fundamentais para estimular o indivíduo autista no entendimento das atividades da vida diária e sua relação com a saúde, desenvolvendo também o raciocínio, a criatividade e a atenção compartilhada.

\section{Contextualizando o Autismo}

De acordo com Código Internacional de Doenças - CID10, o autismo está inserido nos Transtornos Globais de Desenvolvimento com o código CID10 - F84. É um “ (...) Grupo de transtornos caracterizados por alterações qualitativas das interações sociais recíprocas e modalidades de comunicação e por um repertório de interesses e atividades restrito, esteriotipado e repetitivo" (p. 367).

O Manual Diagnóstico e Estatístico de Transtornos Mentais (DSM-V), classifica o transtorno do espectro do autismo (TEA) como um distúrbio do neurodesenvolvimento, caracterizado por déficits na comunicação e interação social e pela presença de comportamentos, interesses ou atividades restritas e repetitivas, desde o início da infância do indivíduo (DSM-5, 2014). Estudos recentes vêm confirmando que o TEA é altamente hereditário e heterogêneo que tem características cognitivas básicas e comumente co-ocorre com outras condições, as chamadas comorbidades (Lord et al, 2020).

A prevalência de TEA pode chegar a 2,2\% (DIETZ et al, 2020). Visto que estudos recentes não relatam diferenças quando analisados fatores étnicos, culturais ou socioeconômicos sobre a prevalência de autismo (Lord et al, 2020), pode-se estimar que o TEA possa atingir mais de 160 milhões de pessoas no mundo, apesar da pouca disponibilidade de dados sobre prevalência oriundos de países de média e baixa renda (Dietz et al, 2020; Lord et al, 2020), o que torna esse transtorno do neurodesenvolvimento como um dos mais frequentes nas últimas décadas.

Diferentemente do CID10, O DSM-5 engloba as questões senso-perceptivas nos critérios diagnósticos, no eixo Comportamentos Restritos e Repetitivos. De fato, questões sensório-perceptivas são muito importantes nos sujeitos com TEA, pois sabe-se que pode ocorrer desorganização nos sentidos. Caminha (2009), traz o relato de vários autores a respeito destes transtornos, conforme mostrado no Quadro 1. 
Quadro 1: Resumo sobre questões sensórios-perceptivas nos sujeitos com TEA.

\begin{tabular}{|c|c|}
\hline Relatos & Artigos /Autores/ano \\
\hline $\begin{array}{l}\text { Entende o autismo a partir de um modelo } \\
\text { sensorial/neurológico no qual, os sintomas do } \\
\text { autismo, como problemas comportamentais, são } \\
\text { consequência de alguma lesão cerebral que faz } \\
\text { com que a criança autista perceba os estímulos do } \\
\text { mundo de forma diferente das não-autistas. }\end{array}$ & $\begin{array}{l}\text { DELACATO, C. H. (1974). The ultimate stranger: the autistic child. Novato, CA: Arena } \\
\text { Press. DOMAN, R., JR. (1986). }\end{array}$ \\
\hline $\begin{array}{l}\text { Define o autismo como envolvendo uma disfunção } \\
\text { sensorial. }\end{array}$ & $\begin{array}{l}\text { MacKAY D. N., GOLLOGLY J. \& McDONALD G. (1986), apud TAYLOR \& FRANCIS } \\
\text { p3-19, published online, (2014). The Doman-Delacato Treatment Methods. } \\
\text { I- Principles of Neurological Organization. The British Journal of Mental Subnormatilty, } \\
\text { v.32, Issue 62. }\end{array}$ \\
\hline $\begin{array}{l}\text { Se refere ao autismo como sendo uma desordem } \\
\text { dos sentidos, onde cada sentido opera de forma } \\
\text { isolada e o cérebro não consegue organizar os } \\
\text { estímulos de modo a obter um significado. }\end{array}$ & $\begin{array}{l}\text { HATCH-RASMUSSEN C. (1995) Sensory integration http://www.autism.org (accessed } \\
\text { July 22, 2020). }\end{array}$ \\
\hline $\begin{array}{l}\text { Considera o autismo como um Distúrbio de } \\
\text { Integração Sensorial no qual o cérebro não } \\
\text { consegue atribuir sentido às sensações. }\end{array}$ & $\begin{array}{l}\text { AYRES A. J., ROBBINS J. (2005). Sensory integration and the child: Understanding } \\
\text { hidden sensory challenges. } 25^{\text {th }} \text { ed. WPS Ed. }\end{array}$ \\
\hline
\end{tabular}

Fonte: Autores.

Seguindo a mesma linha, outras hipóteses sensoriais com relação ao autismo consideram alguns dos comportamentos do transtorno como consequência de uma disfunção no processo de recebimento dos estímulos sensoriais (Caminha, 2009, p.37). Neste contexto, Carroll et al. (2020) defendem que o TEA esteja relacionado com o desequilíbrio da excitação/inibição cerebral e com distúrbio na conectividade. Por exemplo, para impedir uma excessiva entrada de estímulos e trazer mais calma e alívio, indivíduos com TEA sustentam a atenção em ações repetitivas como alinhar objetos, contar, organizar, fixar o olhar em um objeto que se move em círculo, entre outros; assim é possível desligar-se do estímulo incômodo e voltar ao equilíbrio. Dessa forma, o que não é incômodo para um sujeito neurotípico ou para um indivíduo com um nível leve do transtorno, pode ser extremamente perturbador para outro sujeito. Dessa maneira, conseguimos explicar vários dos comportamentos encontrados no TEA, que não são compreendidos por aqueles que não têm o transtorno.

Todos os indivíduos têm um limiar de estimulação social; os sujeitos com TEA apresentam uma baixa aceitação a essa estimulação, por isso, se esse limite é ultrapassado, o sujeito pode passar a apresentar desatenção e afeto negativo; porém, para estímulos não sociais, há facilidade de assimilação. Essa aversão ao estímulo social acaba por impedir a formação do apego ao outro precocemente, também causa transtornos na expressão emocional e na coordenação interpessoal de expressão afetiva (Caminha, 2009; Bittencourt \& Fumes, 2021).

A atenção é outro ponto relevante para tratarmos da questão sensorial do autista, uma vez que para muitos sujeitos a atenção é superseletiva, focando em um único elemento (hiperfoco), dentro de uma série deles. A superseletividade ou hiperfoco auditivo, por exemplo, pode ser uma explicação para as dificuldades do autismo, no que diz respeito a linguagem (Kern et al., 2007).

A mudança de foco da atenção entre as modalidades sensoriais também é algo crítico, apesar de não ser uma impossibilidade. Por causa da dificuldade da passagem entre as modalidades sensoriais, as informações se perdem sobre o contexto e o conteúdo do que está acontecendo ao seu redor. Curiosamente, essa seletividade também pode fazer com que os sujeitos com TEA tornem-se extremamente seletivos para os detalhes, o que os faz tornar-se extremamente capazes em memorização (Mota, 2010). De fato, as pessoas com TEA apresentam reações peculiares a estímulos sensoriais, o que também é relatado no DSM- 5. 
Este fenômeno foi descrito pela terapeuta ocupacional, psicóloga e neurocientista Dra. Anna Jean Ayres, em 1963, como dificuldades na integração sensorial (Serrano, 2018). A integração sensorial é um processo que organiza as nossas sensações, de forma inconsciente e que nos permite viver entre as informações sensoriais e nos concentrarmos em uma atividade específica. Ayres propôs a Teoria da Integração Sensorial, no qual os sentidos captam as informações e enviam ao cérebro que as processam e organiza uma resposta adequada. Entretanto, nas crianças com TEA, esse processo pode encontrar dificuldades (Serrano, 2018).

Há ainda que se destacar que os transtornos sensoriais não são exclusivos do TEA, podendo surgir em inúmeras outras situações de transtorno do desenvolvimento. Os transtornos sensoriais, no entanto, são pouco investigados e sua detecção é feita por relatos de autistas com alta funcionalidade, o que representa um número bastante reduzido de sujeitos e não representa um número grande de pessoas com o transtorno, já que o TEA é muito abrangente, sendo considerado um espectro dentro das características do transtorno e, por isso, não há um sujeito igual ao outro (Jussila et al., 2020).

Sobretudo por causa do Transtorno, é preciso investir no lúdico e na criança, usando-o como elemento facilitador de construção dos conceitos. Brougère (1998) apud Gera (2008), diz entender o jogo educativo como um suporte para a atividade didática; o objetivo seria construir conhecimentos e desenvolver habilidades, por isso é necessária a ação lúdica e educativa.

Contudo, Martins e Goes (2013), dizem que, por causa do autismo, a família, os médicos e terapeutas não agem naturalmente quanto ao brincar, tornando tudo uma obrigatoriedade de terapia ou simplesmente ignorando a necessidade da brincadeira por subestimar o autista. Esses autores relatam:

$\mathrm{Na}$ criança normal, o processo do brincar ocorre de forma natural, em que adultos e parceiros interagem com ela, que logo aprende a agir com objetos de forma lúdica e a compartilhar a atividade. Já nas crianças autistas esse processo não é tão simples, pode ser longo e trazer grandes frustrações a pais, familiares e educadores, que acabam desacreditando da viabilidade e importância dessa área tão propícia ao desenvolvimento. (p.26).

Todavia, compreendendo que o brincar se aprende na relação com o outro, acreditamos que a inclusão escolar possibilita à criança com TEA o encontro, vivências e experiências infantis a partir da relação com outros indivíduos, cada uma em sua singularidade, enfatizando que a criança se constitui como um ser social com e pelo outro, por meio da mediação que a insere no meio cultural (Chiote (2015).

Dadas as caraterísticas do Transtorno do Espectro do Autismo contextualizada até o momento, no que tange o limiar da estimulação social, as questões sensoriais envolvendo hiperfoco e outras características sensório-motoras singulares do autismo, temos o brincar como estratégia para o seu desenvolvimento. Neste sentido, utilizamos uma atividade lúdica, o jogo da Memória Saudável, para trabalhar o conceito de Higiene e Saúde com crianças com diagnóstico de TEA.

\section{O jogo segundo Piaget, Wallon e Vygotsky}

Piaget, Wallon e Vygotsky são teóricos de grande importância nas questões voltadas para o desenvolvimento humano em seu processo ensino-aprendizagem. Suas contribuições partem de aspectos afetivos e cognitivos e apresentam suas visões de forma que o jogo se torna uma estratégia imprescindível para a construção, em específico neste estudo, de conceitos e habilidades de Atividades Básicas da Vida Diária (ABVD) para indivíduos com TEA.

$\mathrm{Na}$ intenção de oportunizar um processo ensino-aprendizagem mais significativo e dinâmico, diferentes materiais e atividades lúdicas são utilizados como motivadores para a apreensão de conceitos e de ampliação da visão de mundo. E pensando no desenvolvimento de forma global, o lúdico corrobora na aquisição de habilidades, na estimulação psicomotora, dos esquemas perceptivos e operativos, na consciência corporal, na socialização e na interação. 
Dessa forma, demonstraremos a importância do jogo como estratégia lúdica na aprendizagem, à luz de Piaget, Wallon e Vygotsky, os quais traziam a idéia do homem como um ser social, construtor de seu próprio conhecimento. Apresentaremos suas concepções de jogo e suas contribuições nesse processo ensino-aprendizagem.

Para Piaget (1978), o jogo apresentava o mesmo significado que brincar, inerente ao universo infantil, sem a associação ao funcionamento cognitivo. O autor ressalta a importância das etapas do desenvolvimento em relação à compreensão do lúdico e sua contribuição na infância e classifica o jogo em três modalidades, relacionando-as a cada fase do desenvolvimento em que surgem: jogos de regras, jogos de exercícios psicomotores e jogos simbólicos. Piaget ressalta que para que um jogo alcance um objetivo educativo, concomitantemente à uma formação psicomotora e o desenvolvimento da personalidade da criança, faz-se necessário interação entre os componentes, levando-os à compreensão de comportamento em grupo, de coletividade. E passa a orientar que atividades serão propostas de acordo com a faixa etária e o desenvolvimento cognitivo de cada criança.

Wallon (Apud Gratiot_Alfandery, 2010), assim como Piaget, propõe etapas do desenvolvimento, classificadas em: impulsivo-emocional, sensório-motor e projetivo, personalismo, categorial e puberdade/adolescência. Segundo o autor, durante este processo de desenvolvimento, a afetividade e o cognitivo de alternam, salientando que o meio social é fundamental para a formação da personalidade da criança. Em sua concepção da relação entre a infância e o lúdico, ressalta a grande relevância do jogo para o desenvolvimento motor, psicológico, cognitivo e social da criança.

Em relação à ludicidade, Wallon classifica os jogos infantis em quatro modalidades: jogos funcionais, jogos de ficção, jogos de aquisição e jogos de fabricação. Os jogos funcionais constituem-se pela exploração do corpo através dos sentidos; os jogos de ficção são atividades lúdicas relacionadas ao faz de conta e à imaginação; os jogos de aquisição caracterizam-se por atividades de compreensão e conhecimento do mundo que os cercam, através da imitação (músicas, histórias, gestos, sons), e os jogos de fabricação constituem-se quando a criança já consegue realizar atividades manuais de criação, de combinação, aglutinação e transformações de objetos.

Vygotsky (1988), diferentemente de Piaget e Wallon, traz uma reflexão sobre os diversos aspectos do desenvolvimento, sem necessariamente estar atrelado à etapas e processos de formação psicológica do nascimento à vida adulta. Ressalta que a aprendizagem, provocada pelo ensino, estimula ciclos de desenvolvimento, que até então estavam ainda insipientes, surgindo novas funções psicológicas superiores, que irão impulsionar mais uma vez o desenvolvimento e, a assim sucessivamente, oportunizando novas aprendizagens.

O autor postula que há dois níveis de desenvolvimento: nível de desenvolvimento real e nível de desenvolvimento proximal. O primeiro refere-se ao que o indivíduo é capaz de realizar sozinho, sem cooperação alguma. O segundo, evidencia que em determinadas situações, o indivíduo só conseguirá realizar algo novo, caso haja auxílio de outra pessoa mais experiente. Neste caminho, entre o que o indivíduo consegue fazer sozinho e o que só faz por intervenção de alguém, encontrase a Zona de Desenvolvimento Proximal (ZDP), onde o sujeito será estimulado a realizar por si mesmo, aquilo que antes só fazia mediante colaboração de outra pessoa.

No que se refere ao jogo, Vygotsky (1988) estabelece uma relação forte entre o desenvolvimento infantil e o brinquedo (brincadeira ou jogo). Para o autor, o brinquedo ou jogo cria uma ZDP na criança, influenciando diretamente em seu desenvolvimento, como um processo gradativo de amadurecimento. E será exatamente a ZDP que irá determinar em que nível real de desenvolvimento cada criança se encontra. Através da imaginação, do brinquedo, do jogo e da brincadeira, a criança constrói sua identidade e sua visão de mundo, em um processo constante de interação.

Vygotsky (2007) traz uma discussão sobre a materialidade do brinquedo, do contexto em que se constituiu e que tipo de conexão faz com a realidade vivida pelas crianças, proporcionando-lhes desenvolvimento psicológico e cultural. Ressalta 
que o brinquedo ou o jogo não se limita apenas a uma atividade prazerosa, mas sim ferramenta mediadora de aprendizagem e desenvolvimento, pertencente ao universo infantil.

O autor complementa:

...se ignorarmos as necessidades das crianças e os incentivos que são eficazes para colocá-la em ação, nunca seremos capazes de entender seu avanço de um estágio de desenvolvimento para outro, porque todo avanço está conectado com uma mudança acentuada nas motivações, tendências e incentivos. (Vygotsky, 2007, p.108)

Por fim, Vygotsky (2008) afirma que todo pensamento se constrói a partir da mediação caracterizada por signos e instrumentos culturais, histórico e socialmente. E que para haver um processo de desenvolvimento, o mesmo " é desencadeado pelas ações das crianças; os objetos com que esta lida representam a realidade e modelam seus processos de pensamento" (p.27). Nesse sentido, o jogo servirá como uma espécie de código, um estímulo externo de representação, para desvendar o mundo que as cercam.

\section{A Ludicidade como estratégia para o desenvolvimento do aluno com TEA}

Pensar em ludicidade é lembrarmos de jogos e brincadeiras, da alegria da infância, da espontaneidade da criança, das brincadeiras de rua, de casinha, de boneca, pique esconde, das invenções e faz de conta. De fato, se nos recordamos de tanta coisa prazerosa é por que jogos e brincadeiras estimulam o desenvolvimento humano em seus aspectos cognitivos e afetivos (Oliveira \& Dias, 2017).

No entanto, definir ludicidade, é tarefa complexa, principalmente, quando consideramos as primeiras etapas da Educação Básica, devido as várias abordagens e estudos sobre o tema. Por isso, consideramos o conceito trazido por Canda (2004), onde a ludicidade é a possibilidade de conduzir práticas educativas de maneira que o ensinar e o aprender se tornam ações interligadas, sendo fundamental ao desenvolvimento integral do ser humano.

A ludicidade permite um maior acesso "ao campo de possibilidades para a imaginação, a criatividade, o desenvolvimento cognitivo e corporal, o reconhecimento da identidade do aluno e a interação social" (Canda, 2004).

Por meio das atividades lúdicas, a criança comunica-se consigo mesma e com o mundo, aceita a existência dos outros, estabelece relações sociais, constrói conhecimentos, desenvolvendo-se integralmente (Oliveira \& Dias, 2017).

Desta forma, acreditamos que o aspecto lúdico é um instrumento essencial na mediação do processo de aprendizagem, principalmente das crianças, favorecendo a concentração, o desenvolvimento social, pessoal e cultural, facilitando o processo de construção do pensamento, conforme mostramos na Figura 1, onde através da ludicidade e suas diferentes possibilidades é possível desenvolver uma vida funcional a indivíduos do Transtorno do Espectro do Autismo. 
Figura 1: Importância da Ludicidade no Desenvolvimento Integral do Ser.

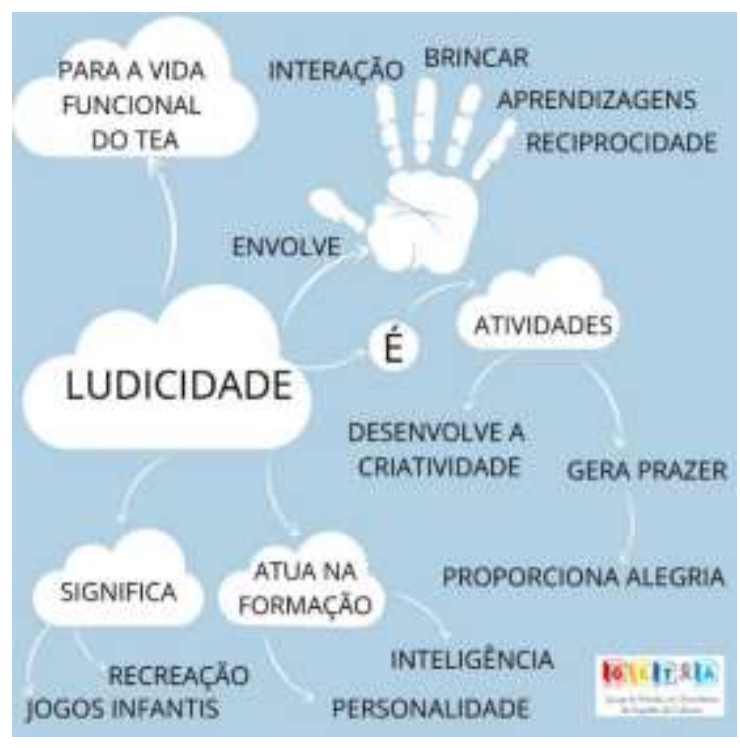

Fonte: Lione e Domiciano (2020) GETEA ${ }^{1}$

É por meio da ludicidade e dos brinquedos que a criança imita o mundo dos adultos, Oliveira e Bossa (1999) apud Aguiar (2017) diz "ao fazer de conta que uma vareta é um carrinho, e movimentá-la pelo chão, imitando o barulho do motor". É desta maneira e de outras, que a criança desenvolve a sua imaginação, criando também situações que ela mesma possa resolver (Porto, 2018).

A literatura em geral descreve o brincar das crianças com o TEA como simples, repetitivo, estereotipado, sem complexidade e diversidade. Segundo Whitman (2015), pesquisas sugerem que as dificuldades nas brincadeiras se dão por causa dos problemas ligados ao processamento sensorial, modulação da excitação, atenção seletiva e mudança do foco de atenção, além de dispraxia e controle executivo. O autor ainda descreve como características desse brincar a ausência de interações funcionais e normativas com brinquedos, além de preocupação com seus detalhes; falta de imaginação e de uma orientação para o "faz-de-conta"; natureza concreta e não simbólica; solidão e qualidade não social.

Tamanaha et al., (2006) realizaram uma pesquisa que avaliou a atividade lúdica livre e dirigida de crianças com o TEA e, a partir do procedimento metodológico adotado, perceberam que o seu brincar era caracteristicamente sensório-motor, porém, também se observou que a mediação do adulto-avaliador, por meio de modelo e incentivo, levou a criança a explorar novas formas de brincar. Isso demonstra a importância do papel do professor como mediador das atividades lúdicas no incentivo ao desenvolvimento de novas formas de brincar.

Diante deste contexto, ressaltamos que é fundamental trabalhar ludicamente com as crianças com TEA, respeitando a singularidades de seu brincar, para que novas experiências e possibilidades sejam proporcionadas. Partimos do pressuposto de que brincar é essencial e faz parte do desenvolvimento humano, entretanto, entendemos que essa atividade não é natural, mas de natureza social, pois "a criança não nasce sabendo brincar, ela precisa aprender, por meio das interações com outras crianças e com os adultos" (Kishimoto, 2010, p. 2). Por isso, destacamos as peculiaridades do brincar das crianças com TEA e insistimos na importância de incentivar as suas formas lúdicas, tendo as primeiras etapas da Educação Básica um cenário favorável para essa ação.

\footnotetext{
${ }^{1}$ GETEA - Grupo de Estudos em Transtorno do Espectro do Autismo, Faculdade de Farmácia - UFRJ
} 
Assim, este artigo discute a importância da adaptação de materiais lúdicos para facilitação da aprendizagem por crianças que apresentam restrições na linguagem. Particularmente, tratamos dos sujeitos que apresentam TEA - Transtorno do Espectro Autista, com baixa funcionalidade da verbalização.

Ao pensar sobre um indivíduo com TEA, geralmente visualizamos um sujeito que apresenta dificuldade com a organização do pensamento e execução da comunicação, bem como o afastamento de seus pares, por isso, nos preocupamos nesse trabalho, em propor uma atividade lúdica, o jogo da Memória Saudável, como mediador pedagógico, com o objetivo de trabalhar o conceito de Higiene e Saúde e desenvolver o pensamento simbólico consciente, relacionado às atividades básicas da vida diária (ABVD) geralmente, prejudicadas em crianças autistas.

Dessa forma, através da elaboração de um jogo da memória sobre Higiene e Saúde foi necessário a utilização de forma lúdica, de conceitos biológicos inerentes ao tema para compreensão dos alunos com TEA, público alvo da nossa pesquisa.

\section{Higiene e Saúde na educação especial}

Os microorganismos como bactérias, fungos, protozoários e algas; e as partículas formadas por cápsula proteica que envolve o material genético, chamadas de vírus, são invisíveis à olho nu, apresentam uma extensa diversidade e estão amplamente distribuídos em nosso planeta. Muitos deles são benéficos e outros patogênicos, ou seja, causadores de doenças aos seres humanos. Como podem estar presentes tanto no interior quanto nas superfícies do corpo humano, muitas vezes, são agentes de contaminações e/ou infecções (Carvalho, 2010). Neste contexto, as doenças infecciosas e parasitoses encontram no ambiente coletivo, condições para serem disseminadas, sendo associadas diretamente à falta de higiene e às condições sanitárias precárias (Maranhão, 2000). Marques e Sakane (2009) relatam que crianças em idade pré-escolar e escolar precoce podem ser contaminadas por endo e/ou ectoparasitas, como protozooses, verminoses e/ou escabiose e pediculose, estas últimas adquiridas por contato interpessoal.

Como os problemas relativos à higiene costumam ocorrer em crianças que convivem em ambientes públicos, estes podem ser diminuídos a partir de um trabalho de conscientização, atingindo consequentemente os pais e a comunidade em geral (Rocha, 2003). Cuidar de crianças de diferentes condições sociais implica lidar com costumes diversos e reconhecer as limitações da escola na educação infantil frente aos problemas econômicos e culturais das famílias, associados à habitação precária, às dificuldades de acesso aos serviços de saúde e a bens básicos para o bem-estar infantil (Maranhão \& Sarti, 2007).

Para a Organização Pan-Americana de Saúde - OPAS (1998), a promoção da saúde no âmbito escolar parte de uma visão integrada e multidisciplinar do ser humano, que considera as pessoas em seu contexto familiar, comunitário, social e ambiental (Gonçalves et al., 2008). Sendo assim, o âmbito escolar deve promover ações visando desenvolver o conhecimento de higiene e prevenção de doenças através de conhecimentos teóricos/práticos.

Diante disso, observamos que ainda existe uma lacuna em relação às investigações sobre o tema, Higiene e Saúde na Educação especial. A literatura demonstra em sua maioria, estudos odontológicos focados na saúde bucal de deficientes visuais (Souza Filho, 2010; Cericato \& Lamha, 2012; Silveira et al., 2015; Monteiro et al., 2018); na higiene oral de pessoas com deficiências intelectuais (Anders et al., 2010; Waltron et al., 2019; Wilson et al., 2019) e em hábitos de higiene oral de crianças com TEA (Hage et al., 2020). Encontramos poucos estudos relacionados à higiene pessoal de surdos (Barbosa \& Maestri, 2016) e de indivíduos com comorbidades visuais e TEA (Probst \& Walker, 2017).

Por ser uma questão de Saúde Pública, e proporcionar a autonomia do sujeito no que tange o conhecimento e cuidado do indivíduo sobre seu corpo; o tema Higiene e Saúde é de extrema relevância. Contudo, pode tornar-se abstrato para o ensino à pessoa com deficiência e pessoas com Transtorno do Espectro Autista, caso não haja uso de materiais que permitam o acesso a esse aprendizado. 
Acerca destas análises, este trabalho abordou os hábitos de higiene e saúde na educação infantil de maneira prática, proporcionando uma aprendizagem lúdica a partir da aplicação do Jogo da Memória Saudável, em sala de aula, para construção do conceito a partir das realidades do grupo de alunos com deficiência.

\section{Metodologia}

Nesta seção, apresentam-se, inicialmente, o público alvo e demais participantes e o local da pesquisa. Em seguida, aborda-se o instrumento de coleta de dados a partir do trabalho de campo realizado. Por fim, são descritos os procedimentos éticos e a produção do jogo e aplicação da atividade lúdica.

\section{Público alvo e demais participantes da pesquisa}

O número total de 13 estudantes, sendo 12 meninos e 1 menina, que apresentavam diagnósticos de autismo moderado à severo, cursando o $3^{\circ}$ ano do ensino básico, foram selecionados para participarem da pesquisa. Além dos professores da sala de recursos multifuncionais (SRM) como mediadores da atividade de pesquisa - auxiliando com a aplicação do jogo.

\section{Local da pesquisa}

A pesquisa foi autorizada em três escolas: Escola Municipal Heitor Dantas, no bairro de Moquetá; Escola Municipal de Educação Infantil Compactor, no bairro de Jardim Iguaçu e o Centro Municipal de Educação Especial Paul Harris, na Posse, todas localizadas no estado do Rio de Janeiro. As três escolas pertencem à Unidade Regional de Governo I (URG I), que são as Unidades Administrativas do município de Nova Iguaçu-RJ.

\section{Instrumento de coleta de dados}

O presente estudo caracterizou-se como uma pesquisa de campo descritiva, cuja abordagem foi qualitativa (Minayo, 2001; Fonseca, 2002; Gil, 2007), uma vez que observamos e avaliamos o comportamento, as falas e experiências dos sujeitos envolvidos (por vezes o relato verbal dos docentes e dos alunos quando possível). A pesquisa qualitativa, em geral, ocorre no ambiente natural com coleta direta de dados a qual permite que o observador, neste caso o professor-pesquisador, possa captar e registrar o comportamento natural do público alvo sem intervenção dos dados (McMillan \& Shumacher, 1997; Pereira et al., 2018).

\section{Procedimentos éticos}

O Jogo da Memória Saudável para Alunos com TEA foi submetido ao Comitê de Ética e Pesquisa da Universidade Federal Fluminense (UFF), cadastrado na Plataforma Brasil com o CAEE 60169416.1.0000.5243 e registrado no Escritório de Direitos Autorais da Fundação Biblioteca Nacional sob o número de protocolo 018939_5/6.

Antes de iniciar a pesquisa, respeitando os aspectos éticos, os pais e responsáveis dos estudantes autistas receberam um Termo de Livre Consentimento e Esclarecimento (TLCE) para que conhecessem os detalhes da atividade proposta e permitissem a participação de seus filhos. Além disso, os professores da sala de recursos multifuncionais (SRM) também receberam o TCLE. Todos eles assinaram o referido termo.

\section{Produção do jogo e aplicação da atividade lúdica}

Para a elaboração do jogo da memória, foi discutido com os professores orientadores da pesquisa, sobre os itens do conteúdo Higiene e Saúde que fariam parte das cartas. Chegou-se a um total de 20 cartas (Figura 2) que formam 10 pares de combinações, do tamanho da metade de uma folha A4 e feitas em E.V.A. (Etil, Vinil e Acetato) para maior firmeza no 
manuseio pelos alunos. As dez placas contêm ilustrações com situações de risco do contato com seres vivos causadores de doenças em nosso corpo: a) criança coçando a cabeça por causa de piolhos; b) pés sujos e descalços; c) unhas compridas e sujas; d) criança com roupas muito sujas; e) água caindo em um copo direto da torneira; f) moscas pousando em alimentos, etc. Do outro lado, dez placas com fotos dos hábitos de higiene relacionados: a) xampu e pente fino; b) sabonete e toalha; c) cortador de unhas; d) filtro e panela fervendo água; e) chuveiro e sabonete; f) roupas estendidas em um varal (Figura 2).

Figura 2: Combinaç̃̃es de peças do Jogo Memória Saudável para Alunos com TEA até o momento do pré-teste.

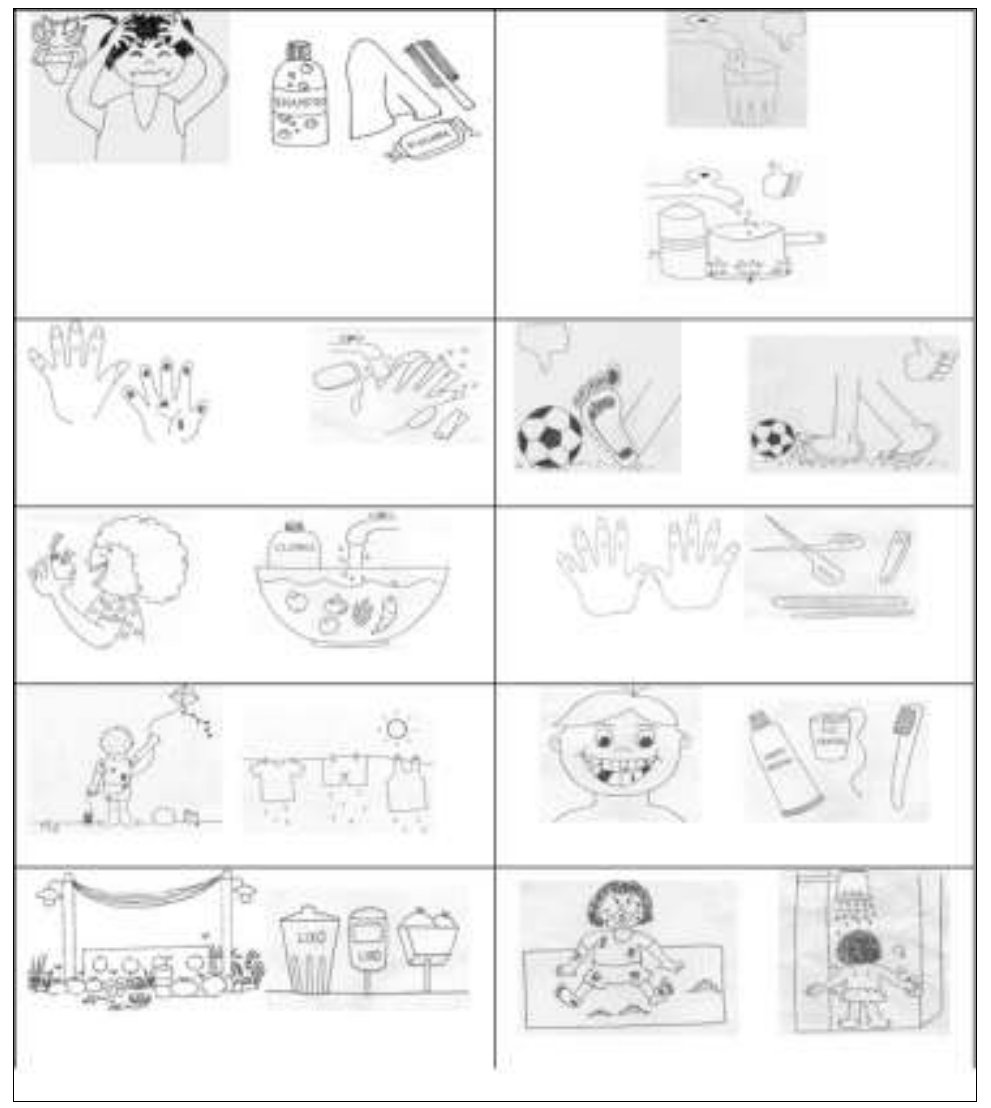

Fonte: Casanova S.A.

Para realização do jogo da memória, as placas devem ser apresentadas com o lado da imagem voltada para cima para que os alunos possam formar os pares junto com o professor. Num segundo momento, as peças são viradas para baixo e as crianças, em pares, com o professor ou entre elas, vão desvirando as placas para realizar o pareamento. Ainda é prevista outra forma de jogar, usando dez cartas como pistas. $\mathrm{O}$ aluno sorteia a carta e tenta encontrar seu par no monte das demais, formando pares lógicos com as informações sobre Higiene e Saúde.

Para a aplicação no espaço escolar, com finalidade de inteirar os professores sobre o jogo e a forma de aplicá-lo, elaboramos um kit de aplicação contendo carta de apresentação com orientações para uso do material; um folheto de instrução para realizar a aplicação do jogo caso o aluno não permitisse a presença da pesquisadora e as imagens do jogo em pares correspondentes. A importância de explicar a dinâmica do jogo para os professores das SRMs, foi pela previsão de que, sendo a rotina e o vínculo com um aluno específico, na possibilidade de rejeição da pesquisadora, o professor poderia participar aplicando o jogo. 


\section{Resultados}

Antes que o jogo fosse desenvolvido com os alunos dentro dos espaços escolares, decidimos realizar uma consultoria sobre o produto com a Profa. Dra. Maria Cristina de Carvalho Delou. A professora destacou a importância de outro contraste para as cores das cartas, sugerindo a substituição da cor azul da base utilizada anteriormente pela cor vermelha (Figura 4); relatou que segundo as pesquisas e a sua experiência, a cor vermelha traria maior conforto visual e menos rejeição do material no critério da sensibilidade para cores.

Ainda de acordo com Delou (2018 - informações pessoais) sobre os ícones de positivo e negativo apresentado em dois pares de cartas (Figura 3), tais figuras não fariam sentido para o autista, podendo confundi-lo; então foram retiradas na segunda versão do jogo. Por último, ela sugeriu que na figura sobre esterilização da água, as imagens relativas ao filtro de água, panela e torneira fossem separadas para favorecer a compreensão da figura, tornando a imagem mais clara.

Figura 3: Ícones positivo e negativo retirados da primeira versão das cartas.
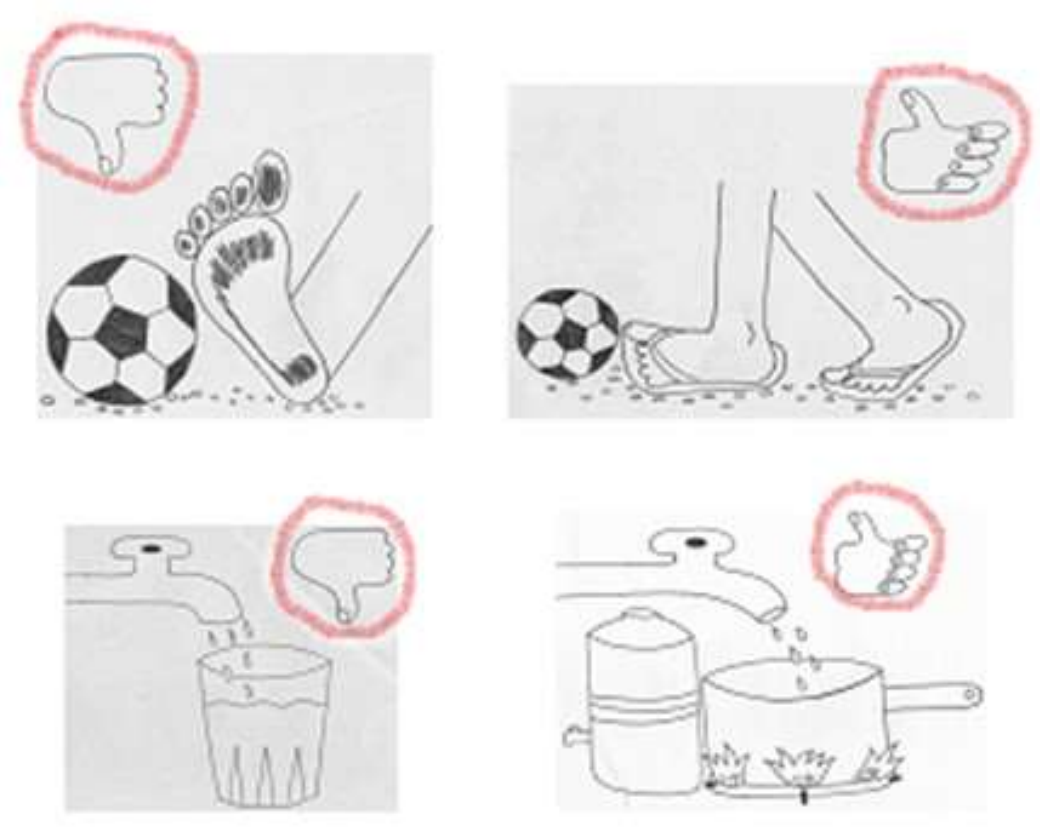

Fonte: Casanova S.A.

A última modificação foi a plastificação de todo material para dar maior durabilidade e favorecer a higienização sempre que necessário, preservando também manter a cor do material (Figura 4). 
Figura 4: Jogo Memória Saudável em versão final.

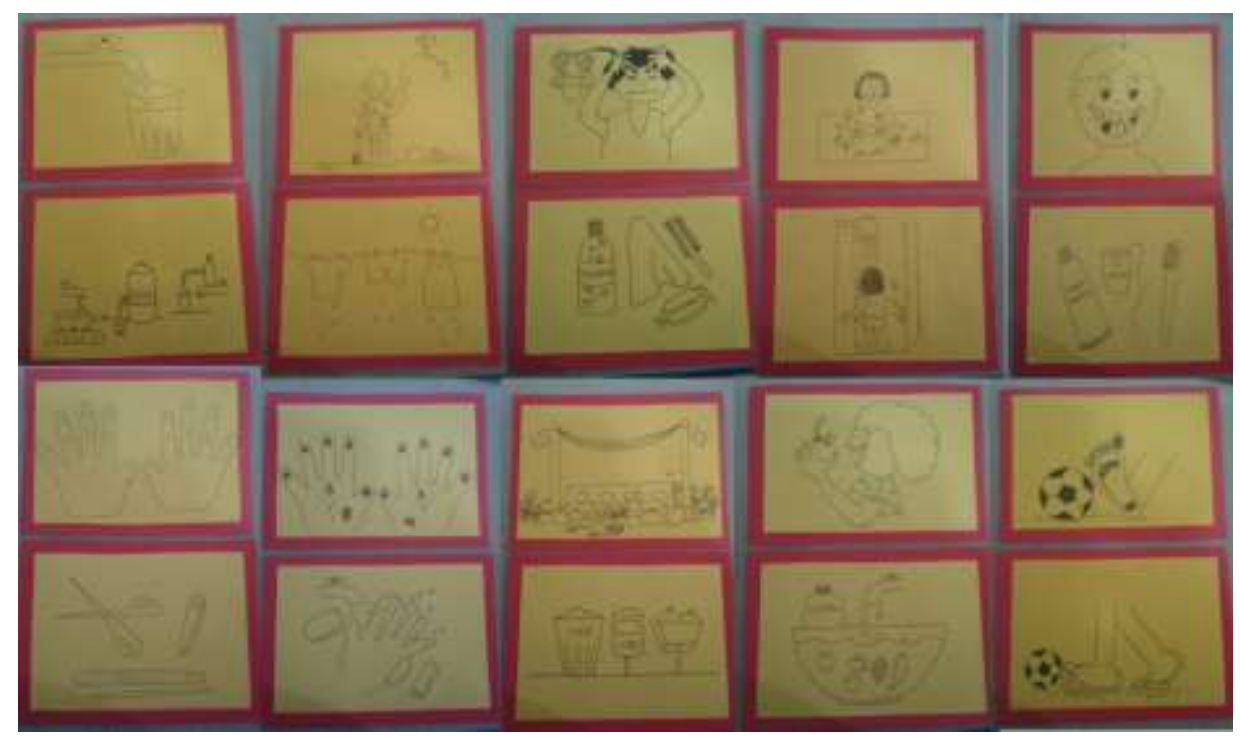

Fonte: Casanova S.A.

Como o nosso objetivo foi objetivo de trabalhar o conceito de Higiene e Saúde e desenvolver o pensamento simbólico consciente, relacionado às atividades básicas da vida diária (ABVD) geralmente, prejudicadas em crianças autistas. Todas as escolas que autorizaram a aplicação do jogo da Memória Saudável acolheram a pesquisa com muita simpatia e os professores se mostraram muito dispostos a colaborar com a atividade lúdica para estudantes com Transtorno do Espectro Autista (TEA).

Os primeiros resultados foram obtidos na SRM da E.M. Heitor Dantas. Três alunos foram indicados pela escola e tiveram a aplicação do jogo da Memória Saudável feita diretamente pela professora da SRM, por causa do vínculo previamente estabelecido, garantindo a aceitação da aplicação do material. No entanto, apenas um menino conseguiu realizar a proposta.

No início, o aluno aceitou a observação à distância, mas agitou-se logo em seguida, o que provocou a saída da pesquisadora de dentro do espaço da sala. $\mathrm{O}$ aluno tinha 10 anos, estudava em turma regular de $3^{\circ}$ ano na mesma escola, estava muito ambientado ao espaço e utilizava PECS (Picture Exchange Communication System - Sistema de Comunicação por Troca de Imagens). O PECS é um sistema visual/simbólico de comunicação onde há troca de figuras, que, utilizando-se do mecanismo expressivo e receptivo da comunicação, leva a pessoa a perceber que é possível realizar desejos através da comunicação (Rodrigues \& Hartmann, 2015). Em nosso campo, essa criança em particular, apesar de não usar a fala, apontou muito rapidamente para a peça que desejava indicar, demonstrando de forma indireta sua resposta.

O segundo local de aplicação do jogo da Memória Saudável foi a Escola Municipal de Educação Infantil Compactor, onde havia cinco crianças com TEA, sendo uma menina; cabe aqui ressaltar que de todas as escolas do estudo, esta foi à única com uma menina autista. Das cinco crianças dessa escola, uma estava ausente, dois deles se recusaram a olhar o jogo da Memória Saudável e dois permaneceram na sala. Desses dois meninos, tivemos resposta efetiva de um aluno de 3 anos que estava com os colegas. A professora relatou que era uma criança que não buscava contato com os demais, mas que ultimamente, estava se mostrando muito aberta para os encontros com os pares, preferindo ficar nas atividades em grupo. Dessa forma, com apoio das duas crianças mais próximas, ele aproximou-se do jogo da Memória Saudável e ficou observando as peças que a professora da SRM apresentava. As outras crianças, que não apresentavam diagnóstico de TEA, respondiam imediatamente mostrando compreender o que era perguntado e facilmente fazendo os pareamentos propostos. A partir deste momento, o menino aproximou-se e pegou um par, olhou e deixou as peças. Como estava aceitando o contato das pessoas e observando os objetos (o que segundo a professora da criança, não conseguia fazer), ficou claro que as condições de compreensão e interação do menino não permitiam que percebesse o que estava sendo apresentado, mas com a participação 
dos outros colegas, voltou o foco e percebeu que havia uma situação de relacionamentos naquele momento: entre as crianças e das crianças com o jogo.

O segundo menino tinha 5 anos e passou muito tempo sem frequentar a escola. Segundo a professora da SRM, a mãe tinha dificuldades para compreender as necessidades da criança e aceitar a existência do TEA, demonstrando inclusive, não saber como lidar com as situações criadas pelo menino e isso parecia levá-la a quase desistir. A criança permaneceu na sala com a pesquisadora (Suzana Assunção Casanova) e com a professora da SRM e foi ela quem fez a apresentação do jogo da Memória Saudável. Possivelmente, por causa do período sem frequentar a escola, não se deteve muito tempo nas imagens, preferindo explorar a sala, o que não pôde caracterizar uma eficaz atuação com o jogo.

A terceira escola, foi o Centro Municipal de Educação Especial Paul Harris, um espaço escolar que anteriormente era uma escola exclusivamente especial, mas que atualmente, possui uma Sala de Recursos Multifuncional e turmas regulares com alunos incluídos. A escola localizada no bairro da Posse, no Rio de Janeiro, apresentava uma lista de oito alunos autistas sendo atendidos na SRM; destes oito, três estavam em período de faltas. A primeira criança foi a que melhor respondeu e interagiu com o jogo da Memória Saudável, conseguindo formar sozinho, pelo menos 5 pares de cartelas; o segundo aluno necessitou de redução do número de peças para conseguir se concentrar e responder (Figura 5). As três últimas crianças apresentaram dificuldade de compreensão ou não demonstraram interesse pelo jogo (Figura 6).

Figura 5: Uso do jogo com o aluno. Primeiro encontra uma carta e depois realiza o pareamento.

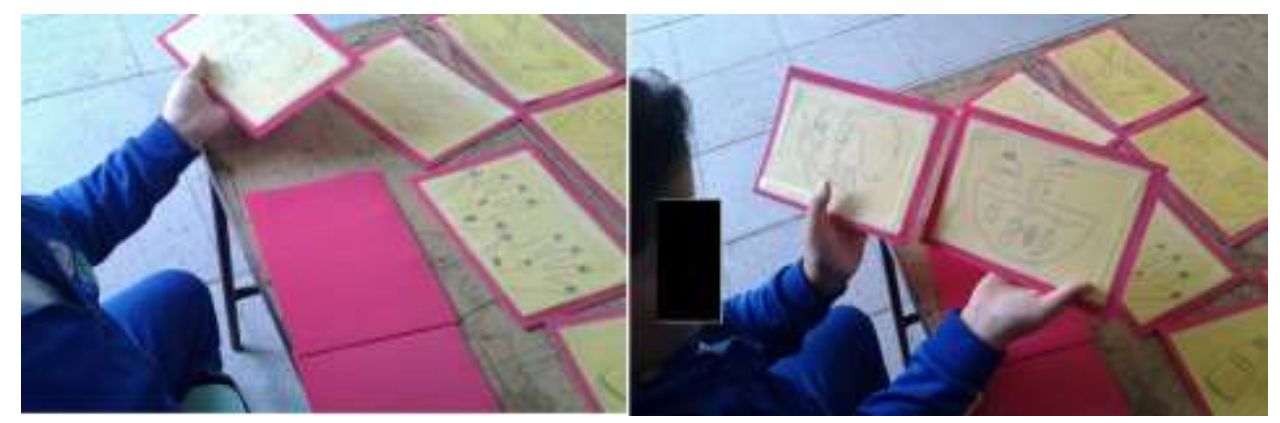

Fonte: Casanova S.A.

Figura 6: Aluno sob intervenção direta para realizar a proposta Jogo Memória Saudável.

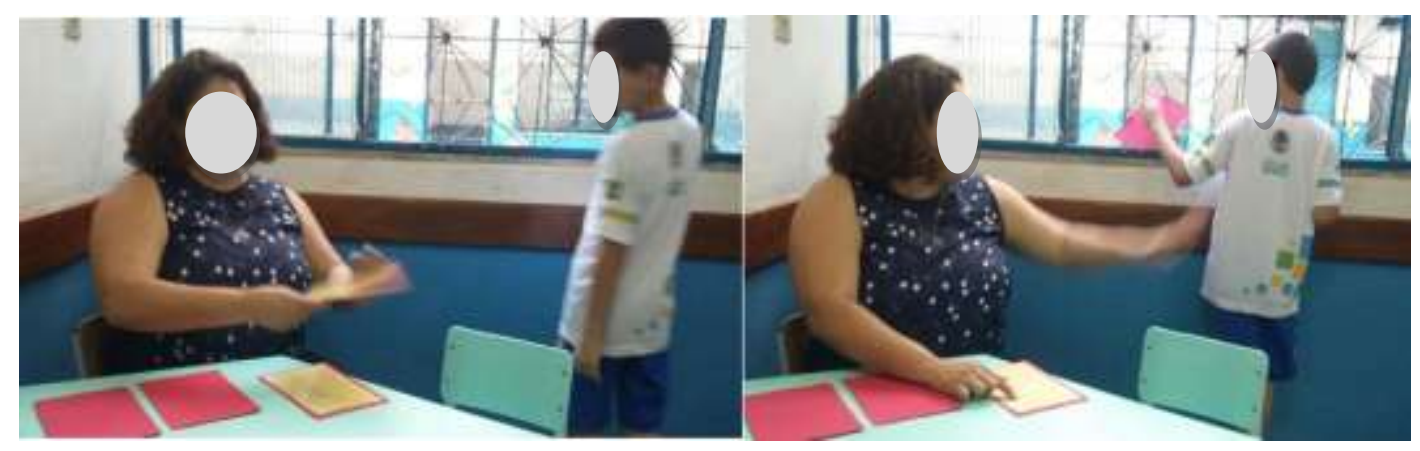

Fonte: Casanova S.A.

\section{Discussão}

Neste artigo discutimos a importância da adaptação de materiais lúdicos para facilitação da aprendizagem por crianças que apresentam restrições na linguagem como sujeitos que apresentam TEA - Transtorno do Espectro Autista, com baixa funcionalidade da verbalização. 
Durante o estudo foi possível perceber não apenas diferenças diante dos diagnósticos de cada aluno, mas diferenças entre os próprios indivíduos. Muito embora todos apresentassem o diagnóstico de TEA e tivessem a mesma característica da dificuldade com a verbalização. O que evidencia a caracterização do autismo como algo tão complexo, que os critérios para diagnóstico se modificam ao longo das décadas. Até a década de 80, o autismo entrava na classificação das psicoses e somente com a publicação do DSM-III foi descrito como transtorno e não mais como psicose infantil. Nessa edição III do manual entravam o autismo e o transtorno global do desenvolvimento sem outra especificação; somente na publicação do DSM-IV foram introduzidos a Síndrome de Asperger, a Síndrome de Rett e o Transtorno Desintegrativo, quando as classificações também foram para o CID-10, tal como descrevem (Brunoni et al., 2014).

A aplicação do jogo da Memória Saudável foi prevista para ser realizada com um total de 13 estudantes, sendo 12 meninos e 1 menina, que apresentavam diagnósticos de autismo moderado à severo, cursando o $3^{\circ}$ ano do ensino básico. Embora a escolha da amostra tenha sido aleatória (de acordo com o número de alunos com TEA matriculados nas escolas que autorizaram a pesquisa) a maioria dos estudantes com TEA eram indivíduos do sexo masculino, o que corrobora com relatos da literatura, que indicam baixa incidência de TEA em crianças do sexo feminino (Lai et al. 2015).

A adaptação das cores das cartas do jogo, como sugerido pela Profa Dra Cristina Delou, favoreceu a melhor identificação das imagens. De fato, encontramos na psicologia das cores o arcabouço para tal mudança. Segundo essa teoria, não existe cor destituída de significado, pois a cor é algo além de apenas um fenômeno ótico (Heller, 2013). Em sua pesquisa, Heller demostrou que cores e sentimentos não se combinam ao acaso, nem são uma questão de gosto individual, mas são vivências comuns que, desde a infância, foram enraizadas em nossa linguagem e em nosso pensamento. Assim, a escolha correta das cores e suas combinações podem ser um grande aliado do aprendizado do aluno com autismo, poupando tempo e esforços para conseguir alcançar o objetivo pedagógico proposto (Mota, 2015; Moraes, 2019).

É importante ressaltar que a metodologia utilizada foi pesquisa de campo descritiva, com abordagem qualitativa (Holliday, 2002), cuja coleta de dados se baseou na observação direta sem intervenção dos dados (Pereira et al., 2018). Dessa forma, avaliamos o comportamento, as falas e experiências dos sujeitos envolvidos (por vezes o relato verbal dos docentes e dos alunos quando possível). De acordo com Souza et al., (2019) trabalhar com pessoas com TEA exige um treinamento específico que possa esclarecer o saber sobre e o saber como. Esta observação corrobora com o nosso trabalho quando observamos que a convivência com os alunos autistas conferiu aos professores a capacidade de prever o que cada criança poderia fazer no jogo e elaborar estratégias adaptadas às competências para produzir resultados que equilibrassem os excessos e a ausência de repertórios comportamentais. Através da adaptação, foi permitido que a criança apontasse os pares correspondentes ao invés de virá-los, mantendo o contato visual. A estratégia da participação dos professores promoveu a construção de novas respostas, deixando o jogo mais acessível de acordo com as possibilidades de cada aluno. Por isso, cabe destacar a importância do conhecimento do professor sobre seu aluno. As falas dos professores foram de extrema importância para a análise dos dados, bem como para observar como se dá a dinâmica de ensino e aprendizagem com os alunos com Transtorno do Espectro Autista (TEA). Os professores ainda comentaram sobre a importância de se ter ações de pesquisas constantes que apoiem o trabalho em sala de aula e permitam a produção de novos materiais, além de informações atualizadas sobre TEA, bem como as demais deficiências.

Refletindo sobre as formas de interação de sujeitos com TEA, bem como o desenvolvimento do pensamento e da linguagem, utilizando o jogo como intervenção no processo ensino-aprendizagem, neste trabalho, destacamos os teóricos Jean Piaget, Henri Wallon e Lev Vygotsky para alicerçar as discussões, em se tratando da concepção de jogo e sua relação com o desenvolvimento. De acordo com Vygotsky (1988), a mediação é um conceito fundamental, bem como para os pesquisadores envolvidos nesse estudo, pois acreditamos que a mediação pedagógica permite a aprendizagem e foi esta ação que fez toda a diferença no momento da aplicação do jogo. Em nosso trabalho, observamos que a intervenção das outras crianças, que não 
apresentavam diagnóstico de TEA, foi fundamental para que o aluno com TEA percebesse a situação e interagisse naquele momento; neste caso, os colegas atuaram como mediadores da situação. Segundo Oliveira (2010, p.33) a mediação é um processo essencial para tornar possível as atividades psicológicas voluntárias, intencionais, controladas pelo próprio indivíduo. Quanto mais mediamos às situações, trabalhando com questionamentos e conceitos que permitam ao aluno movimentar-se entre o que se sabe (zona de desenvolvimento real) e o que pode vir a saber, (zona de desenvolvimento proximal), mais o que levaremos a alcançar novos saberes (zona de desenvolvimento potencial) (Vygotsky, 1988).

Neste sentido, destacamos objetivos pedagógicos traçados para o jogo da Memória Saudável e o seu alcance. Ficou bastante claro que as crianças mais velhas, com idades entre 9 a 10 anos responderam melhor do que as crianças mais jovens. Entendemos então, que as crianças com mais idade já tiveram mais experiências, inclusive com situações cotidianas de vida como os hábitos de higiene e cuidados pessoais. Esses dados corroboram com o relato de pesquisa sobre Autismo e interações escolares (Lemos et al., 2020) que também evidenciaram um comportamento diferencial em crianças que foram melhor orientadas a partir das ordens verbais, pois mesmo não se expressando oralmente, apresentaram compreensão em todas as situações. Pressupõe-se que se os alunos mais velhos, tiveram mais vivências. Parece que justamente por causa da necessidade de conhecimentos prévios, o jogo Memória Saudável para alunos com TEA, também tenha melhor aplicação como material para avaliação e verificação da aprendizagem, pois a criança já teria possibilidade de ter vivido outras experiências.

Também por este dado relacionado à faixa etária e vivências/experiências, compreendemos que o jogo da Memória Saudável pode ser classificado por idade ou ser indicado somente para alunos a partir do $3^{\circ}$ ano de escolaridade, por volta de 9 anos. Como os alunos de Educação infantil tem menos vivências/experiências, inclusive com a escola, as rotinas e os conceitos, indicamos usar até cinco pares com situações mais usuais dos cuidados pessoais seria o adequado: sujar-se e tomar banho, lavar as frutas e verduras, lavar as mãos, aparar as unhas, usar roupas limpas (que seria associado também a tomar banho), relacionado às atividades de vida diária. As peças mais complexas como o tratamento contra piolhos, ingerir água filtrada e as demais, seriam indicadas para autistas com grau mais complexo de raciocínio e mais vivências.

Vale destacar o importante papel do educador de criar condições para ampliar experiências de brincadeiras na relação entre as crianças com deficiência e as demais crianças, sendo essencial a mediação para condução da criança ao lúdico. Contudo, na Educação Infantil, quem vivencia esse papel não pode se prender à limitação do diagnóstico de autismo, mas sim, abrir-se às possibilidades, orientando-se não pelo que a criança faz/ou não faz, mas investindo naquilo que ela pode vir a fazer, focando na potencialidade da criança (Chiote, 2015).

É preciso desconstruir o olhar tradicional sobre a deficiência como defeito, falha, menos. Vygotsky (2011) reforça esse entendimento ao defender que a deficiência, embora produza obstáculos no desenvolvimento, cria caminhos alternativos e indiretos de adaptação, substituindo funções e trazendo ao sistema de equilíbrio uma nova ordem. Segundo Vygotsky (2011):

Eis por que a história do desenvolvimento cultural da criança permite propor a seguinte tese: o desenvolvimento cultural é a principal esfera em que é possível compensar a deficiência. Onde não é possível avançar no desenvolvimento orgânico, abre-se um caminho sem limites para o desenvolvimento cultural (Vygotsky, 2011, p. 870).

Assim, com base em Vygotsky (2011), é através da necessidade da criança de comunicar-se com o seu meio circundante que ela é impulsionada à passagem do desenvolvimento natural para o desenvolvimento cultural. Essa teoria traz uma nova perspectiva para o olhar sobre as crianças como TEA tendo na Educação infantil, em suas brincadeiras e interações, um cenário favorável para impulsionar o seu desenvolvimento.

Muito embora Martins e Goes (2013), digam a partir da fala de Vygotsky que na brincadeira a criança usa regras de comportamento e valores sociais que possivelmente não seriam usadas por ela fora da brincadeira, não foi assim que aconteceu 
durante este jogo. Vygotsky (1991) diz que na brincadeira o sujeito comporta-se para além do que é esperado para a sua idade e torna-se maior do que realmente é, contudo, possivelmente tal fato ocorra durante as brincadeiras em que se envolvem regras sociais, não acontecendo no jogo, onde eram necessários conceitos estabelecidos anteriormente.

Todavia, é necessário frisar que os jogos como atividade lúdica trazem em si inúmeros benefícios, que envolve, segundo Piaget (1998) uma abrangência de significados, sendo a linguagem afetiva uma dessas formas de expressão, cuja estrutura é o símbolo. Piaget ainda traz que o brincar reflete os estados internos do sujeito diante de uma realidade vivida ou imaginada (Nicolau, 1998).

Os estudos de Piaget (1998) contribuem principalmente ao analisarem o simbolismo secundário do jogo, traduzido como sendo "o simbolismo menos consciente que o das ficções comuns" (p. 217), ou seja, o jogo de ficção corresponde a construção mais importante na criança, que é o pensamento simbólico consciente.

Em relação à aprendizagem, a ludicidade oferece indícios relevantes a respeito dos aspectos emocionais envolvidos no processo de conhecer e de aprender, conforme resumimos na Figura 7:

Figura 7: Benefícios dos Jogos para o Desenvolvimento do Ser.

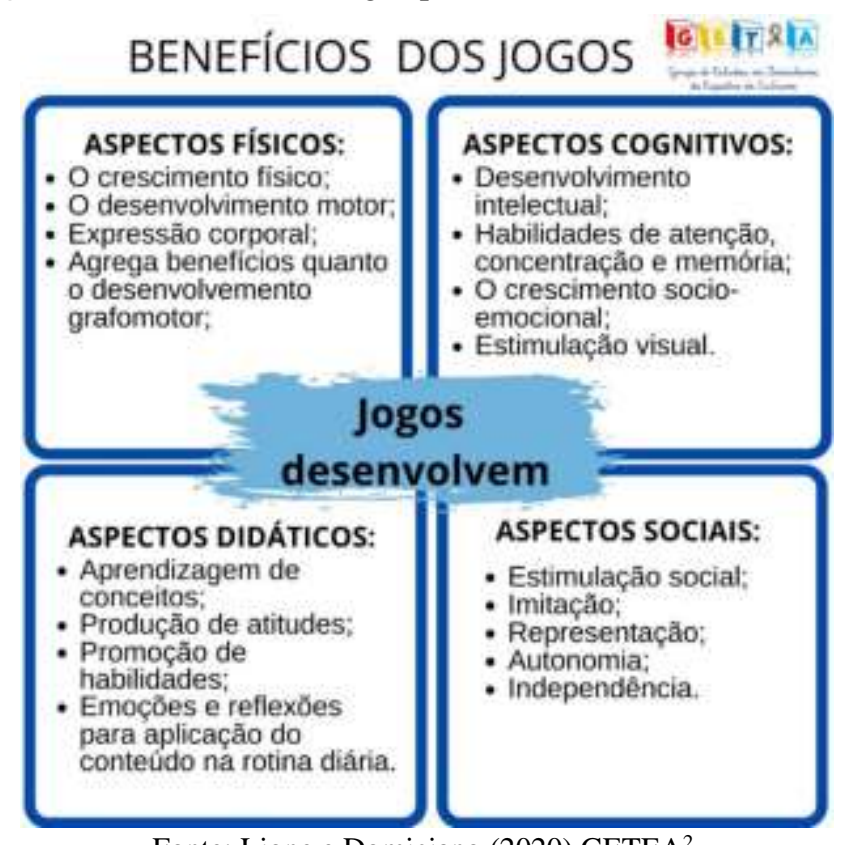

Fonte: Lione e Domiciano (2020) GETEA ${ }^{2}$

Sobre as experiências observadas no campo quanto a usabilidade do jogo da Memória Saudável, sugere-se usar material concreto como elemento facilitador para auxiliar em conhecimentos prévios, principalmente, para as crianças menores. Desta forma, é importante apresentar material de uso pessoal para higiene como sabonete, escova de dentes, pastas de dentes, xampu e sabonete para combater piolhos, entre outros. O uso de material visual e tátil para compor o jogo, pode auxiliar a contextualizá-lo.

O tamanho das peças mostrou-se indiferente, não havendo necessidade de serem tão grandes. Quanto ao uso de desenhos ao invés de fotos, também se mostrou eficaz, possibilitando a compreensão, o que é importante, pois configura um jogo de baixo custo quanto a sua elaboração. Nesse sentido, vale ressaltar que o uso de imagens em desenho já é utilizado por autistas, por exemplo, no PECS citado como meio de comunicação alternativa neste trabalho, em que a criança usa desenhos para apontar seus desejos, necessidades e estabelecer comunicação. O PECS foi desenvolvido em 1993, por Bondy \& Frost

\footnotetext{
${ }^{2}$ GETEA - Grupo de Estudos em Transtorno do Espectro do Autismo, Faculdade de Farmácia - UFRJ
} 
(Whitman, 2015), sendo um dos principais sistemas de comunicação alternativa utilizada por autistas e sujeitos que tenham comprometimento de desenvolvimento associados. Locatelli \& Santos (2016) relatam que o uso de material com figuras como a PECS, são materiais simples, de boa acessibilidade e tem a possibilidade de desenvolvimento em diversos contextos sociais, quer por profissionais especializados, quer pelos pais da criança, desde que tenham conhecimento necessário para tal ou que sejam orientados de forma adequada por terapeutas ou educadores.

Finalmente, vale ressaltar a importância e a escassez de pesquisas sobre o tema Higiene e Saúde na educação especial. Mesmo diante das dificuldades, como as encontradas nesta pesquisa, como ausência dos alunos promovendo a diminuição do número esperado de indivíduos para aplicação do jogo, além da rejeição de outros alunos para realização da atividade lúdica, precisamos buscar novas metodologias ativas que possibilitem a estruturação do pensamento simbólico e a construção de comportamentos e habilidades que favoreçam a autonomia no que tange às atividades básicas da vida diária (ABVD) e ao autocuidado dos alunos com TEA e outras necessidades educacionais especiais.

\section{Considerações Finais}

Uma vez que os alunos escolhidos como alvo da pesquisa foram autistas não verbais, o jogo da Memória Saudável se mostrou eficaz quando tivemos interação com outros sujeitos, pois através dele, professores e demais crianças conseguiram uma atividade comum envolvendo os sujeitos com TEA.

Observamos ainda que o jogo poderá também ser aplicado como verificador da aprendizagem além de elemento para ensinar o conteúdo, pois obtivemos melhores respostas quando os sujeitos da pesquisa apresentavam experiências anteriores com o material de higiene e/ou realizavam autocuidados com autonomia, evidenciado com as crianças mais velhas. Todavia, partindo do pressuposto dos benefícios dos jogos, outras habilidades, principalmente as relacionadas a estrutura do pensamento simbólico podem ter sido despertadas nas crianças menores.

Consideramos que principal ganho obtido com a aplicação do jogo foram as interações entre sujeitos independentemente da idade. Outro aspecto positivo, foi a possibilidade de flexibilização do material, pois o professor poderá usar todo o jogo, reduzir seu número de cartelas ou ainda selecionar aquelas que mais se aplicam ao que gostaria de trabalhar dentro do tema Higiene e Saúde com o seu público alvo.

Por fim, sugerimos que o tema Higiene e Saúde seja cada vez mais trabalhado na educação especial e que outros materiais lúdicos acessíveis como o Jogo da Memória Saudável sejam desenvolvidos para promover o processo de construção de conceitos e do pensamento simbólico, favorecendo assim, a vida funcional desses indivíduos.

\section{Agradecimentos}

Ao Curso de Mestrado Profissional em Diversidade e Inclusão (CMPDI); às escolas E.M. Heitor Dantas; Escola Municipal de Educação Infantil Compactor e o Centro Municipal de Educação Especial Paul Harris pelo apoio e parceria dos docentes. E especialmente à Profa Dra Maria Cristina de Carvalho Delou pelos direcionamentos baseados em sua vasta experiência no assunto.

\section{Referências}

Aguiar, S. B. S. M. A Ludicidade Infantil. (2017). Revista Científica Multidisciplinar Núcleo do Conhecimento, 2 (1), $495-507$.

Amorim, C. \& Peruzzo Junior, L. (2006). O brincar e o desenvolvimento humano. Psicologia Argumento, 24 (46), 91-94.

Anders, P. L., \& Davis, E. L. Oral health of patients with intellectual disabilities: A systematic review. (2010). Special Care in Dentistry, 30 (3), 110-117. 10.1111/j.1754-4505.2010.00136.x 
Barbosa, A. L. \& Maestri, M. (2016). Educação e saúde: orientações sobre higiene pessoal em uma escola bilíngue para surdos. In: Desafios da escola pública paranaense na perspectiva do professor PDE. Cadernos PDE, (1), 1-14.

Brougère G. (1998). A criança e a cultura lúdica. Revista da Faculdade de Educação, (24)2, Dossiê. doi.org/10.1590/S0102-25551998000200007.

Bittencourt, I. G. S. \& Fumes, N. L. F. (2021). "I shouldn't have gotten out of there! I like to study!" The challenges of people with Autism Spectrum Disorder for schooling. Research, Society and Development, (10): 5, e12610514681. 10.33448/rsd-v10i5.14681. https://rsdjournal.org/index.php/rsd/article/view/14681.

Brunoni, D., Mercadante, M. T. \& Schwartzman, J, S. (2015). Transtornos do espectro do Autismo. Avaliação e Comorbidades em Alunos de Barueri, São Paulo. Psicologia, 18 (1), 166-177. http://dx.doi.org/10.15348/1980-6906.

Caminha, R. C. (2009). Autismo: Um Transtorno de Natureza Sensorial? Psicologia Clínica, 21 (1). Dissertação de mestrado, Pontifícia Universidade Católica do Rio de Janeiro. doi.org/10.1590/S0103-56652009000200030

Canda, C. N. (2004). Aprender e brincar é só começar. In: Porto, Bernadete de Souza (Org.). Educação e ludicidade. Salvador: Universidade Federal da Bahia, Faculdade de Educação, Programa de Pós-Graduação em Educação, Gepel, 123-140.

Carvalho, I. T. (2010). Microbiologia Básica. EDUFRPE.

Carroll, L., Braeutigam, S., Dawes, J. M., Krsnik Z., Kostovic, I., Coutinho, E., Dewing, J. M., Horton C. A., Gomez-Nicola, D. \& Menassa D. A. (2020). Autism Spectrum Disorders: Multiple Routes to, and Multiple Consequences of, Abnormal Synaptic Function and Connectivity. The Neuroscientist, 1-20.

Cericato, G. O. \& Lamha, A. P. S. F. (2012). Hábitos de saúde bucal de portadores de deficiência visual no contexto da saúde coletiva. Revista da Faculdade de Odontologia, 17 (2), 137-144.

Chiote, F. A. B. (2015). Inclusão da Criança com Autismo na Educação Infantil: trabalhando a mediação pedagógica. Wak Editora.

Coll, C., Marchesi, A., Palacios, J., Baptista, C. R. \& Murad, F. (2007). Desenvolvimento Psicológico e Educação - Transtornos de Desenvolvimento e Necessidades Educativas Especiais. Porto Alegre: Editora ArtMed.

Cunha, E. (2014). Autismo e inclusão: psicopedagogia e práticas educativas na escola e na família. Wak Editora.

Declaração de Salamanca (1994). Sobre princípios, políticas e práticas na área das necessidades educativas especiais. Salamanca - Espanha.

Dietz, P. M., Rose, C. E., McArthur, D., Maenner M. (2020). National and State Estimates of Adults with Autism Spectrum Disorder. Journal of Autism and Developmental Disorders, 50, 1-9.

Fonseca, J. J. S. (2002). Metodologia da pesquisa científica. UEC.

Foucault, M. (2001). Os anormais. Martins Fontes.

Ferreira, A. L. \& Acioly-Régnier, N. M. (2010). Contribuições de Henri Wallon à relação cognição e afetividade na educação. Curitiba: Educar Editora UFPR.

Freitas, M. T. A. (1999). O Pensamento de Vygotsky e Bakhtin no Brasil. Papirus.

Galvão, I. (2012). Henry Wallon: Uma Concepção Dialética do Desenvolvimento Infantil. Vozes.

Gera, M. Z. F. \& Tassinari, A. M. (2008). O espaço do brincar na educação infantil: um estudo em creches e pré-escolas. In: IX Encontro de Pesquisadores do Uni-FACEF, Franca/SP. Anais do IX Encontro de Pesquisadores do Uni-FACEVF.

Gil, A. C. (2007). Como elaborar projetos de pesquisa. Atlas.

Glat, R. \& Pletsh, M. D. (2013). Estratégias educacionais diferenciadas para alunos com necessidades especiais. EdUERJ.

Gonçalves F. D., Catrib A.M.F., Vieira N. F. C., de Souza Vieira, L. J. E. (2008). A promoção da saúde na educação infantil. Interface, 12 (24). https://doi.org/10.1590/S1414-32832008000100014

Gratiot-Alfandéry, H. (2010). Henri Wallon. Editora Massangana.

Hage, S. R. V., Lopes-Herrera, S. A., Santos T-H. F., Defense-Netvral, D. A., Martins A., Sawasaki L. Y. \& Fernandes F. D.M. (2020). Oral hygiene and habits of children with autism spectrum disorders and their families. Journal of Clinical and Experimental Dentistry, 1:12 (8), e719-e724. 2020. $10.4317 /$ jced.56440.

Heller, E. (2013). A psicologia das cores: como as cores afetam a emoção e a razão. Gustavo Gili.

Holliday A. (2002). Doing and Writing qualitative research. Sage Publication.

Jomtien, Tailândia: UNESCO. (1990). Declaração mundial sobre educação para todos e plano de ação para satisfazer as necessidades básicas de aprendizagem. Disponível em: https://www.unicef.org/brazil/declaracao-mundial-sobre-educacao-para-todos-conferencia-de-jomtien.

Jussila, K., Junttila, M. J., Kielinen, M., Ebeling H., Joskitt L., Moilanen I., Mattila M. L. (2020). Sensory Abnormality and Quantitative Autism Traits in Children with and without Autism Spectrum Disorder in an Epidemiological Population. Journal of Autism and Developmental Disorders, 50, $180-188$.

Kern, J. K., Trivedi, M. A., Grannemann, B. D., Garver, C. R., Johnson, D. G., Andrews, A. A., Savla, J. S., Mehta, J. A. \& Schroeder, J. R. (2007). Sensory correlations in autism. Autism, 11(2) 123-134. 10.1177/1362361307075702 
Kishimoto, T. M. (ORG). (2002). O brincar e suas teorias. Pioneira.

Klin, A. (2006). Autismo e Síndrome de Asperger: uma visão geral. Revista Brasileira de Psiquiatria, 28(1). 3-11.

Lai, M.-C., Lombardo, M. V., Auyeung, B., Chakrabarti, B., Baron-Cohen, S. (2015). Sex/Gender Differences and Autism: Setting the Scene for Future Research. Journal of the American Academy of Child \& Adolescent Psychiatry, 54 (1), 11-24. https://doi.org/10.1016/j.jaac.2014.10.003

Locatelli, P. B. \& Santos, M. F. R. (2016). Autismo: Propostas de Intervenção. Revista Transformar, 8, 203-220.

Lord, C., Brugha, T. S., Charman, T., Cusack J., Dumas, G., Frazier T., Jones, E. H., Jones, R. M., Pickles A., State, M. W., Taylor, J. L. \& VeenstraVanderweele J. (2020). Autism spectrum disorder. Nature Reviews Disease Primers, 6 (1):5. 10.1038/s41572-019-0138-4.

Mantoan, M. T. E. (2005). Inclusão é o Privilégio de Conviver com as Diferenças. Nova Escola.

Maranhão, D. G. (2000). O cuidado com o elo entre saúde e educação. Cadernos de Pesquisa, 111, 115-133. https://doi.org/10.1590/S010015742000000300006.

Maranhão, D. G. \& Sarti C. A. (2007). Cuidado compartilhado: negociações entre famílias e profissionais em uma creche. Interface - Comunicação, Saúde, Educação. 11 (22), 257-70.

Marques, H. H. de S. \& Sakane, P. T. (2009). Infestações por protozoários na infância / Protozooal infestations in childhood. Pediatria moderna, 45 (4):125138.

Martins, A. D. F. \& Goes, M. C. R. (2013). Um estudo sobre o brincar de crianças autistas na perspectiva histórico-cultural. Revista Semestral da Associação Brasileira de Psicologia Escolar e Educacional, 17 (1), 25-34.

Menassa D. A. (2020). Autism Spectrum Disorders: Multiple Routes to, and Multiple Consequences of, Abnormal Synaptic Function and Connectivity. The Neuroscientist, p. 1-20.

Minayo, M. C. S. (2001). Pesquisa social: teoria, método e criatividade. Vozes.

McMillan, J. H. \& Shumacher, S. (1997). Research in Education. Addison Wesley Educational Publishers Inc.

Monteiro, L. P. A., Monteiro, A. C. C., Pereira, R. M., Costa, I. C. C. (2018). O conhecimento de deficientes visuais em relação à saúde bucal. Revista Ciência Plural, 4 (1), 44-66.

Moraes, C. B. X. (2019). Apostila adaptada, uma possibilidade de alfabetização de alunos com autismo. Dissertação de Mestrado em Diversidade e Inclusão Curso de Mestrado Profissional em Diversidade e Inclusão - CMPDI- Universidade Federal Fluminense. Niterói, Rio de Janeiro, RJ, 94p.

Mota, A. C. W. (2010). Diretrizes clínico-educacionais para intervenção no processo de desenvolvimento psicológico de crianças com espectro autista. Dissertação de mestrado, UFSC- Florianópolis, SC, 343 p.

Mota, A. Di P. (2015). Identificação de transtornos do espectro de autismo com Child Behavior Checklist (CBCL): Evidências de sensibilidade. Tese de Doutorado. USP - São Paulo, SP, 106 p. 10.11606/T.47.2015.tde-12082015-151126.

Nicolau, M. L. M. (1998). A educação pré-escolar, fundamentos e didática. Ática.

Oliveira, V. B. (1999). Avaliação psicopedagógica da criança de 0 a 6 anos. Vozes.

Oliveira, C. M. de \& Dias, A. F. (2017). A Criança e a Importância do Lúdico na Educação. Revista Científica Multidisciplinar Núcleo do Conhecimento, 2 (1):13, 113-128.

Oliveira, M. K. (2010). Vygotsky: aprendizado e desenvolvimento, um processo sócio-histórico. Scipione.

OPAS. (1998). Escuelas promotoras de la salud: entornos saludables y mejor salud para las generaciones futuras. Washington, EUA, 32p.

Organização Mundial da Saúde. (2009). CID-10/Organização Mundial da Saúde: tradução Centro Colaborador da OMS para a Classificação de Doenças em Português. 10 (1):1. São Paulo: Editora da Universidade de São Paulo, USP.

Ortiz Huerta, J. H. (2014). Terapia de Integración Sensorial em Niños com Transtorno de Espectro Autista. TOG (A Coruña) 19 (11), 1-13.

Pereira A. S., Shitsuka, D. M., Parreira, F. J., Shitsuka, R. (2018). Metodologia da pesquisa científica. UFSM. https://repositorio.ufsm.br/bitstream/handle/1/15824/Lic_Computacao_Metodologia-Pesquisa-Cientifica.pdf?sequence=1

Piaget, J. (1978). A formação do símbolo na criança: imitação, jogo e sonho, imagem e representação. Zahar.

Porto, S. G. S. (2018). Ludicidade: um caminho para ressignificar a prática pedagógica e o desenvolvimento da criança na educação infantil. Revista Científica Multidisciplinar Núcleo do Conhecimento, 3 (8):12, 72-83.

Probst, K. M., \& Walker, V. L. (2017). Using the System of Least Prompts to Teach Personal Hygiene Skills to a High School Student with Comorbid Visual Impairment and Autism Spectrum Disorder. Journal of Visual Impairment \& Blindness, 111 (6), 511-526. 10.1177/0145482x1711100603

Relvas, M. P. (2009). Fundamentos Biológicos da Educação: despertando inteligências e afetividade no processo de aprendizagem. Wak Editora.

Rocha, H. H. P. (2003). Educação escolar e higienização da infância. Caderno Cedes, 23 (59), 39-56.

Rodrigues, J. M. C. \& Hartmann, E. D. S. (2015). A criança autista: um estudo psicopedagógico. Wak Editora. 
Research, Society and Development, v. 10, n. 8, e28910817318, 2021

(CC BY 4.0) | ISSN 2525-3409 | DOI: http://dx.doi.org/10.33448/rsd-v10i8.17318

Santos, C. C. S., Costa, L. F. \& Martins, E. (2015). A prática educativa lúdica: uma ferramenta facilitadora na aprendizagem na educação infantil. Ensaios Pedagógicos Revista Eletrônica do Curso de Pedagogia das Faculdades OPET, 74-89.

SBP_ Sociedade Brasileira de Pediatria. Documento Científico Triagem precoce para Autismo/Transtorno do Espectro Autista (2017). Departamento Científico de Pediatria do Desenvolvimento e Comportamento. http://www.sbp.com.br/fileadmin/user_upload/2017/04/19464b-DocCient-Autismo.pdf.

Serrano, P. (2018). A integração sensorial no desenvolvimento e aprendizagem da criança. Ed. Papa-Letras.

Silveira, E. R., Schardosim, L. R., Goettems, M. L., Azevedo, M. S. \& Torriani, D. D. (2015). Educação em Saúde Bucal Direcionada aos Deficientes Visuais. Revista Brasileira de Educação Especial, 21 (2), 289-298.

Souza Filho, M. D., Nogueira, S. D. M. \& Carvalho e Martins, M. C. (2010). Avaliação da saúde bucal de deficientes visuais em Teresina-PI. Arquivos em Odontologia, 45 (2), 66-74.

Tamanaha, A. C., Chiari B. M., Perissinoto J. \& Pedromônico M. R. A. (2006). Atividade Lúdica no Autismo Infantil. Distúrbios da Comunicação, 18 (3), 307-312.

Waldron, C., Nunn, J., Mac Giolla Phadraig, C., Comiskey, C., Guerin, S., Van Harten, M. T. \& Clarke, M. J. (2019). Oral hygiene interventions for people with intellectual disabilities. Cochrane Database of Systematic Reviews, 5 (012628), 1-187. 10.1002/14651858.cd012628.pub2.

Wallon, H. (2007). A Evolução Psicológica da Criança. Editora WMF Martins Fontes.

Wilson, N. J., Lin, Z., Villarosa, A., Lewis P., Philip, P., Sumar B. \& George A. (2019). Countering the poor oral health of people with intellectual and developmental disability: a scoping literature review. BMC Public Health, 19 (1530), 1-16. https://doi.org/10.1186/s12889-019-7863-1.

Whitman, T. L. (2015). O desenvolvimento do autismo: Social, Cognitivo, Linguístico, Sensório-motor e Perspectivas Biológicas. Books do Brasil.

Vygotsky, L. A. (1988). Formação social da mente: O desenvolvimento de processos psicológicos superiores. São Paulo: Editora Martins Fontes.

Vygotsky, L. A. (2003). Psicologia pedagógica. Artmed.

Vygotsky, L. A. (2007). A formação social da mente. Martins Fontes.

Vygotsky, L. A. (2008). Pensamento e linguagem. Martins Fontes.

Vygotsky, L. A. (2011). A defectologia e o estudo do desenvolvimento e da educação da criança anormal. Revista Educação e Pesquisa, 37 (4), $861-870$. https://www.scielo.br/scielo.php?script=sci_arttext\&pid=S151797022011000400012. 